\title{
Retraction Note: Mountain environment detection and power transformer fault diagnosis based on edge computing
}

\section{Zhengqin $\mathrm{Li}^{1}$}

Published online: 22 November 2021

(c) Saudi Society for Geosciences 2021

Retraction Note: Arabian Journal of Geosciences (2021) 14: 934

https://doi.org/10.1007/s12517-021-07214-z

The Editor-in-Chief and the Publisher have retracted this article because the content of this article is nonsensical. The peer review process was not carried out in accordance with the Publisher's peer review policy. The author has not responded to correspondence regarding this retraction.

The original article can be found online at https://doi.org/10.1007/ s12517-021-07214-z.

Zhengqin Li

zhengqinlee@126.com

1 Wenzhou University Oujiang College, Wenzhou 325035,

Zhejiang, China 